
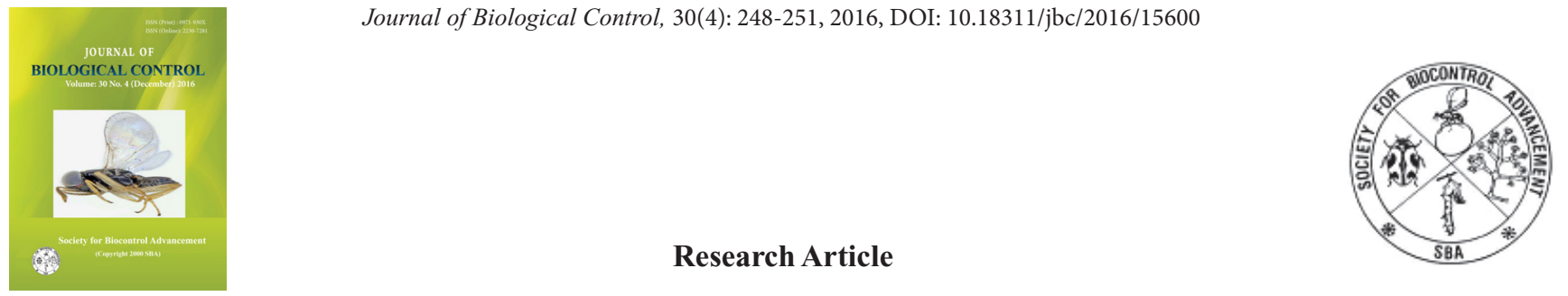

Seasonal incidence of spider mite Tetranychus ludeni Zacher (Tetranychidae: Acari) and its predator Scolothrips sexmaculatus Pergande (Thysanoptera: Insecta) on carnation (var. Master) from Himachal Pradesh, India

\title{
VIJAY SINGH* ${ }^{*}$ and USHA CHAUHAN
}

Department of Entomology, College of Horticulture, Dr Y S Parmar University of Horticulture and Forestry, Nauni, Solan - 173230 , Himachal Pradesh, India

*Corresponding author Email: vijay4chandel@gmail.com

\begin{abstract}
Study was conducted on carnation (var. Master) during 2013 and 2014 under polyhouse. Infestation of Tetranychus ludeni Zacher was recorded. One species of predatory thrips viz. Scolothrips sexmaculatus Pergande was recorded in association with T. ludeni. Infestation of T. ludeni remained active throughout the year. Maximum population was recorded during June in both the years. Population was $13.2 \pm 1.24$ and $14.4 \pm 1.57$ mites/sample. Activity of $S$. sexmaculatus was recorded from June to August. Both species were recorded for the first time on this crop from North India. Population of T. ludeni and S. sexmaculatus was positively correlated with temperature whereas negative correlation with relative humidity. This study will be useful in bio control of phytophagous mites in IPM programme.
\end{abstract}

KEY WORDS: Tetranychus ludeni, Scolothrips sexmaculatus, carnation, Himachal Pradesh

(Article chronicle: Received: 11-10-2016; Revised: 11-11-2016; Accepted: 14-12-2016)

\section{INTRODUCTION}

Climatic conditions of Himachal Pradesh are suitable for cultivation of fruit, vegetable and ornamental crops. Economy of farmers in this state mainly depends on cultivation of different horticultural crops. With the introduction of polyhouses in the state, farmers grow vegetables and ornamental crops under protected conditions. Due to economic importance these play a key role in uplifting the economy of farmers in various parts of the state. Due to high demand and reasonable market value, these crops attracted the interest of farmers in this state to grow these crops on commercial scale under polyhouse. Carnation (Dianthus sp.) is one of the important exotic ornamental crop and most popular as cut flower in the world and of highest economic importance in the floriculture industry. In India, it is covering more than 600 ha of area and mostly grown under polyhouse (Shukla and Radadia, 2015). Various pests attack this crop under polyhouse and harm its economic value. Polyhouse provide a favourable environment suitable for the growth and multiplication of different pests.

Mites of family Tetranychidae are considered as one of the important pests, even in moderate infestation greatly affects crop production and in heavy infestation cause death of the plants (Jeppson et. al., 1975). Two spotted spider mite, Tetranychus ludeni Zacher has been reported to attack more than 150 species of economically important crops (Xie et al., 2006). Tetranychus ludeni thrive and reproduce throughout the year under polyhouse conditions. So, timely management practices are needed for their effective control. World over these pests are known for their ability to develop acaricidal resistance on various crops due to their short life cycle and high reproductive potential (Devine et al., 2001; Stumpf and Nauen, 2001; Sridhar and Jhansi Rani, 2003; 2007; Craham \& Helle, 1985; Goodwin et al, 1991). Therefore, the use of natural enemies a part of IPM programme is the best alternative to reduce their population below economic injury level and overcome the problem of resistance. Various workers throughout the world reported number of natural enemies in association with spider mites (Abad-Moyano et al., 2009; Thistlewood, 1991; Wilson et al., 1991).

Considering the importance of these pests, there is an urgent need to understand their seasonal activity and associated natural enemies. Little information is available from this region on the seasonal incidence of this pest and its natural enemies under protected conditions. Therefore, in the present study an attempt was made to know the seasonal 
activity of the pest and its natural enemy on carnation under polyhouse.

Study was conducted during 2013 and 2014 on "Master" variety of carnation under polyhouse at experimental farm, Department of Floriculture and Landscaping. Data was recorded throughout the year at fifteen days interval, two observations of the month were summed up to get one observation. Samples of thirty leaves/buds were randomly selected and placed in well labelled polythene bag tied with rubber band. These bags were kept in refrigerator at $5^{\circ} \mathrm{C}$ overnight to immobilize the mites and thrips. Samples were observed under stereo zoom microscope (Olympus SZX9) and motile stages were counted carefully. Mean population and standard error of mean was calculated through ANNOVA.

Correlation was calculated between population of T. Iudeni and S. sexmaculatus with weather factors under polyhouse. The impact of abiotic factors viz. average temperature and relative humidity the time of observation was made by calculating the simple correlation (r).

\section{Identification}

For identification the mite specimens were mounted in a drop of Hoyer's medium (Singh and Raghuraman, 2011; Jeppson et al., 1975). Slides were dried in hot air oven at $35-40^{\circ} \mathrm{C}$ for $4-5$ days. Specimens were identified under phase contrast microscope by following the standard keys (Gupta and Gupta, 1994).

For mounting of thrips, specimens were mounted in a drop of Hoyer's media (Jeppson et al., 1975). Specimens were placed on a cover slip in a drop of Hoyer's media and stretched with the help of needles. Slide was kept over it carefully and was re-inverted. Then the slides were dried in oven at $35{ }^{\circ} \mathrm{C}$ for $6-7$ days.

Specimens were observed and identified under Olympus CX41 phase contrast microscope by following the keys given by Ananthakrishnan and Sen (1980).

\section{Seasonal incidence of Tetranychus Iudeni and Scolo- thrips sexmaculatus during 2013}

Infestation of T. ludeni was recorded throughout the year. Population during January, 2013 was $3.6 \pm 0.51$ mites per sample. Increasing trend was recorded from February to May with population of $3.8 \pm 0.49$ (February), $4.4 \pm 0.74$ (March), 5.4 \pm 0.74 (April) and 6.6 \pm 1.12 (May) mites per sample, respectively. Peak incidence was observed in the month of June i.e. $13.2 \pm 1.24$ mites per sample. The population declined during July to August i.e. $7.2 \pm 0.49 \& 5 \pm 0.44$ mites per sample. Increase in population observed during the months of September and October i.e. 5.2 \pm 0.58 and $6.4 \pm 0.51$ per sample. Population again declined from November to December. During these months population was $3.2 \pm 0.58$ (November) \& $2 \pm 0.31$ (December) mites per sample (Figure 1).

The incidence of predatory thrips was confined to June and July months and was conspicuously not observed during all other months. Population of $S$. sexmaculatus in the month of June and July was $0.4 \pm 0.40 \& 3.2 \pm 0.37$ per sample, respectively (Figure 1).

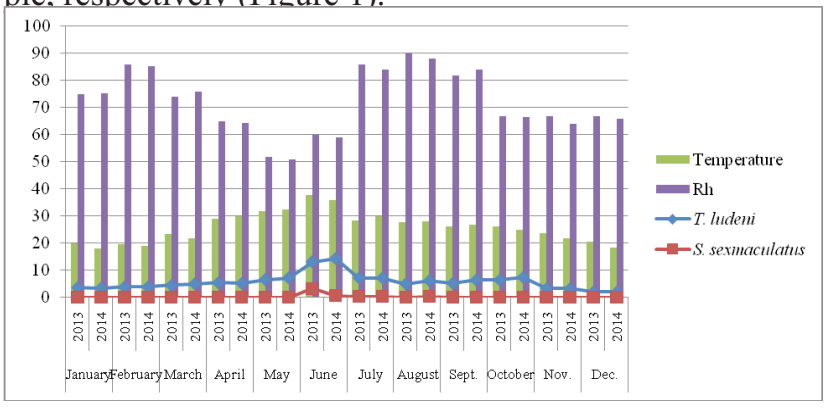

Fig. 1. Seasonal incidence of Tetranychus Iudeni and Scolothrips sexmaculatus on carnation (var. Master) during 2013 and 2014.

Seasonal incidence of Tetranychus Iudeni and Scolothrips sexmaculatus during 2014

During 2014, the population of mite was $3.4 \pm 0.4$ per sample in the month of January. The population was increased from February to May. In these months the population was 3.8 \pm 0.20 (February), 5.0 \pm 0.45 (March), 5.2 \pm 0.37 (April) and 7.2 \pm 0.49 (May) mites per sample, respectively. Population reached peak during June (14.4 \pm 1.57 mites/ sample). The incidence declined from July to August (7.2 $\pm 0.49 \& 6.2 \pm 0.80 \mathrm{mites} / \mathrm{sample})$. Population increased in the month of September (6.4 $\pm 0.51 \mathrm{mite} / \mathrm{sample})$. Minor peak was observed during the month of October $(7.4 \pm 0.40$ mites/sample). Population declined with the fall in temperature from November to December with $3.2 \pm 0.66 \&$ $2.0 \pm 0.31 \mathrm{mites} / \mathrm{sample}$, respectively (Figure 1).

During 2014, the incidence of predatory thrips was recorded in June, July and August months and not observed during other months. Population of $S$. sexmaculatus during June to August was $0.6 \pm 0.40,0.4 \pm 0.40$ and $0.2 \pm 0.20$ per sample, respectively (Figure 1). This concluded that the predator needs to be conserved, multiplied for augmentative releases for effective use as a biocontrol agent in near future which may reduce the use of chemical pesticide which are harmful to other beneficial organism as well.

Earlier, Tetranychus ludeni Zacher was reported on Dahlia sp. from this state by Sood and Kakar (1990). 
Results of population increase and decrease were in conformity with the study of Patil et al. (2014). They reported the population of T. urticae on carnation. Population attain its peak in June and October months. Shukla and Radadia (2015) reported the peak population of spider mite on carnation during April under polyhouse on carnation whereas population peak was recorded during July by Shah and Shukla (2014). Patil (2010) revealed that incidence of T. urticae was started from the last week of February and increased gradually to reach its peak during first week of July (34.51 mite/plant) on carnation under polyhouse, these results support the present findings.

Rawat and Modi (1969) reported predaceous bug, Geocoris tricolor and a number of other coccinellids as general predators of Tetranychus spp. from Jabalpur (Madhya Pradesh). Puttaswamy and ChannaBasavanna (1980) reported Stethorus pauperculus Weise, Oligota oviformis (Casey) and Scolothrips sexmaculatus (Pergande) predating upon T. ludeni. Rai et al. (1999) reported predatory thrips Scolothrips indicus (Thripidae) in association with population of phytophagous mites.

\section{Correlation study with climatic factors}

The population of T. ludeni and S. sexmaculatus was correlated with climatic factors under polyhouse conditions i.e. temperature and relative humidity. During 2013, population of T. urticae showed a highly positive correlation with temperature $(\mathrm{r}=0.894)$ whereas population of S. sexmaculatus was positively correlated with temperature $(\mathrm{r}=0.701)$. Population of these species were negatively correlated with relative humidity i.e. T. ludeni $(\mathrm{r}=-0.298)$ and S. sexmaculatus $(\mathrm{r}=-0.297)$. During 2014, mite population was highly positive correlated with temperature $(\mathrm{r}=0.841)$ and negatively correlated with relative humidity $(\mathrm{r}=-0.261)$ while in case of thrips the population was highly positive correlated with temperature $(\mathrm{r}=0.649)$ and showed a positive correlation with the relative humidity $(\mathrm{r}=0.001)$ Table 1 .

These results were supported by Shukla and Radadia (2015), who reported positive correlation between spider mite population and temperature while population was negatively correlated with relative humidity under polyhouse conditions on carnation from Gujarat. Shah and Shukla (2014) reported that mite population showed negative correlation with temperature and positive correlation with relative humidity on gerbera under polyhouse.
Table 1. Correlation of Tetranychus Iudeni Zacher and Scolothrips sexmaculatus Pergande population with the climatological factors on carnation (var. Master)

\begin{tabular}{lcccc}
\hline Climatic Factors & \multicolumn{2}{c}{ T. ludeni } & \multicolumn{2}{c}{ S. sexmaculatus } \\
\hline & 2013 & 2014 & 2013 & 2014 \\
\hline Temperature $\left({ }^{\circ} \mathrm{C}\right)$ & 0.894 & 0.841 & 0.701 & 0.649 \\
Relative Humidity $(\%)$ & -0.298 & -0.261 & -0.296 & 0.009 \\
\hline
\end{tabular}

\section{ACKNOWLEDGEMENT}

The authors are highly thankful to Head, Department of Entomology for providing the necessary facilities, Dr. S. K. Gupta (Former Joint Director, ZSI, Kolkata) for confirming the mites identification and Dr. Vikas Kumar (Scientist C, ZSI, Kolkata) to confirm the thrips identification.

\section{REFERENCES}

Abad-Moyano R, Pina T, Dembiilio O, Ferragut F, Urbaneja A. 2009. Survey of natural enemies of spider mites (Acari: Tetranychidae) in citrus orchards in eastern Spain. Exp Appl Acarol. 47(1): 49-61.

Ananthakrishnan TN, Sen S. 1980. Taxonomy of Indian Thysanoptera. Zoological Survey of India (Handbook Series) 1: 1-234.

Craham JE, Helle W. 1985. Pesticide resistance in Tetranychidae. pp. 405-32. In: Helle, Sabelis MW (Eds) World Crop Pests, Spider Mites, Their Biology, Natural Enemies and Control, Elsevier, Amsterdam.

Devine GJ, Barber M, Denholm PS. 2001. Incidence and inheritance of resistance to acaricides in European strains of the two-spotted spider mite (Tetranychus urticae) (Acari. Tetranychidae). Pest Mgmt Agric Sci. 57: 443-448.

Goodwin S, Gough N, Herron G. 1991. Miticide resistance and field control in two spotted mite, Tetranychus urticae Koch infesting roses. Proceeding of 1st National Conference, Australian Society of Horticultural Science, Macquarie University Sydney, Australia $325-25$.

Gupta SK, Gupta YN. 1994. A taxonomic review of Indian Tetranychidae (Acari. Prostigmata) with description of new species, re-descriptions of known species and key to the genera and species. Memoirs Zool Surv India 18(1): 1-162. 
Jeppson LR, Keiffer HH, Baker EW. 1975. Mites injurious to economic plants - Handbook. University of California Press, Berkley, California.

Patil D, Patel KA, Toke NR, Ambule A. 2014. Population dynamics of Tetranychus urticae Koch (Acarina: Tetranychidae) of carnation under protected conditions. Trends Biosci. 7(15): 2007-2009.

Puttaswamy, Channa Basavanna GP. 1980. Influence of three Amaranthis species on the development, fecundity and longevity of Tetranychus neocalidonicus (Acari: Tetranychidae). Colemania 1: 35-36.

Rawat RR, Modi BN. 1969. New host record of predaceous bug Geocoris tricolor Fabr. (Hygaeidae : Heteroptera) from India. Indian J Entomol. 31: 74.

Rai AB, Malaviya MD, Desai HR, Patel JR. 1999. Impact of date of sowing, weather factors and natural enemies on the incidence of T. ludeni and role of botanicals in its control and safety to the predatory mite. $J$ Acarol. 14: $105-108$.

Sanjta S, Chauhan U. 2015. Survey of thrips (Thysanoptera) and their natural enemies in vegetables from mid hills of Himachal Pradesh. The Ecoscan. 9(3\&4): 713-715.

Shah DR, Shukla A. 2014. Seasonal incidence of spider mite, Tetranychus urticae (Koch) (Tetranychidae : Acari) on gerbera (Gerbera jamesonii) under polyhouse conditions. Pest Mgmt Hort Ecosyst. 20(1): 26-29.

Shukla A, Radadia GG. 2015. Seasonal incidence of spider mite, Tetranychus urticae (Koch.) infesting carnation (Dianthus caryophyllus L.) under polyhouse conditions. Pest Mgmt Hort Ecosyst 21(1): 46-48.
Singh J, Raghuraman M. 2011. Emerging scenario of mite pests in India. Zoosymposia 6: 172-179.

Sood AK, Kakar KL. 1990. Record of non-insect pests of ornamental plants from Himachal Pradesh. $J$ Insect Sci. 3(2): 141-45.

Sridhar V, Jhansi Rani B. 2003. Relative susceptibility in open and greenhouse populations of two-spotted spider mite, Tetranychus urticae Koch on rose to dicofol. Res Pest Mgmt. Newsletter. 12: 83.

Sridhar V, Jhansi Rani B. 2007. Resistance in two-spotted spider mite, Tetranychus urticae Koch on rose from different polyhouses to dicofol and wettable sulphur. J Acarol. 17: 48-50.

Stumpf N, Nauen R. 2001. Cross-resistance, inheritance, and biochemistry of mitochondrial electron transport inhibitor- acaricide resistance in Tetranychus urticae (Acari: Tetranychidae). J Econ Entomol. 94: 15771583.

Thistlewood HMA. 1991. A survey of predatory mites on Ontario apple orchards with diverse pesticide programs. Can Entomol. 123: 1163-1174.

Wilson LT, Trichilo PJ, Gonzalez D. 1991. Natural enemies of spider mites (Acari: Tetranychidae) on cotton: Density regulation or casual association? Environ Entomol. 20(3): 849-856.

Xie L, Miao H, Xiao-Yue Hong XY. 2006. The two spotted spider mite Tetranychus urticae Koch and the carmine spider mite Tetranychus cinnabarinus (Boisduval) in China mixed in their Wolbachia phylogenetic tree. Zootaxa 1166: 33-46. 